\title{
Cavia porcellus as a Model for Experimental Infection by Trypanosoma cruzi
}

Yagahira E. Castro-Sesquen, ${ }^{*}$ Robert H. Gilman, ${ }^{\dagger}$ Verónica Yauri, ${ }^{*}$ Noelia Angulo, ${ }^{*}$ Manuela Verastegui, ${ }^{\neq}$ Daniel E. Velásquez, ${ }^{\S}$ Charles R. Sterling, ${ }^{\natural}$ Diana Martin, ${ }^{\S}$ and Caryn Bern ${ }^{\S}$

From Asociación Benéfica PRISMA,* San Miguel, Lima, Peru; the Department of International Health, ${ }^{\dagger}$ Bloomberg School of Hygiene and Public Health, Johns Hopkins University, Baltimore, Maryland; the Department of Microbiology, ${ }^{\ddagger}$ Universidad Peruana Cayetano Heredia, Lima, Peru; the Division of Parasitic Diseases and Malaria, ${ }^{\S}$ Center for Global Health, Centers for Disease Control and Prevention, Atlanta, Georgia; and the Department of Veterinary Science and Microbiology, "Iniversity of Arizona, Tucson, Arizona

The guinea pig (Cavia porcellus) is a natural reservoir for Trypanosoma cruzi but has seldom been used as an experimental infection model. We developed a guinea pig infection model for acute and chronic Chagas disease. Seventy-two guinea pigs were inoculated intradermally with $10^{4}$ trypomastigotes of $T$. cruzi strain Y (experimental group); 18 guinea pigs were used as control group. Eight animals from the experimental group and two from the control group were sacrificed $5,15,20,25,40,55,115,165$, and 365 days after inoculation. During the acute phase (15 to 55 days), we observed parasitemia (with a peak on day 20) and positive IgM and IgG Western blots with antished acute-phase antigen bands. The cardiac tissue showed vasculitis, necrosis (on days 40 to 55), moderate to severe inflammation, and abundant amastigote nests. Smaller numbers of amastigote nests were also present in kidney, brain, and other organs. In the early chronic phase (115 to 165 days), parasitemia disappeared and anti- $T$. cruzi IgG antibodies were still detectable. In cardiac tissue, the number of amastigote nests and the grade of inflammation decreased. In the chronic phase (365 days), the cardiac tissue showed vasculitis and fibrosis; detectable parasite DNA was associated with higher grades of inflammation. The experimental $T$. cruzi infection model in guinea pigs shows kinetics and pathologic changes similar to those of the human disease. (Am J Pathol 2011, 179:281-288; DOI: 10.1016/j.ajpath.2011.03.043)
Chagas disease, caused by the protozoan parasite Trypanosoma cruzi, is one of the most important parasitic infections of the Americas. Despite successful vector control programs in many countries, the disease remains a major public health problem in Latin America, with 8 to 10 million people currently infected, an annual incidence of 65,000 new cases in 15 countries, and 14,000 deaths associated with the infection per year. ${ }^{1}$

Transmission to the mammalian host occurs when a $T$. cruzi-infected triatomine vector deposits infectious trypomastigotes in feces during a blood meal and the parasites invade through the bite wound or intact mucosal membranes. ${ }^{2}$ Trypomastigotes can infect virtually any nucleated cell, where they transform to amastigotes and replicate in the host cell cytoplasm. Amastigotes convert back to trypomastigotes inside the cell and then rupture the cell and circulate in the bloodstream. After weeks, the host immune response usually controls the acute infection but does not completely clear the parasite. This results in lifelong chronic infection of the host.

The initial weeks after T. cruzi infection are characterized by a high-level parasitemia and symptoms that vary from mild nonspecific febrile illness to life-threatening myocarditis and/or meningoencephalitis. ${ }^{2}$ Acute symptoms and detectable parasitemia resolve spontaneously within 2 to 3 months, and the infected individual passes into the chronic phase of the disease. Nearly all individuals in the early period of chronic infection are asymptomatic and are said to have the indeterminate form of the disease. In most individuals, the infection remains silent for life and is detectable only by anti-T. cruzi serologic tests and, in a proportion of individuals, by molecular

Supported by NIH training grant in infectious and tropical diseases 5 T35 Al065385 and NIH grant 1R01Al087776-01.

Accepted for publication March 29, 2011.

The funding sources had no role in the study design; the collection, analysis, and interpretation of the data; the preparation of the manuscript; or the decision to submit for publication. The findings and conclusions in this report are those of the authors and do not necessarily represent the views of the Centers for Disease Control and Prevention.

Address reprint requests to Robert H. Gilman, M.D., Department of International Health, Johns Hopkins University, Bloomberg School of Hygiene and Public Health. 615 N. Wolfe St., Room W\#5515, Baltimore, MD 21205. E-mail: rgilman@jhsph.edu. 
techniques. However, over years to decades, $10 \%$ to $30 \%$ of patients develop chronic manifestations, most commonly progressive cardiomyopathy. ${ }^{3}$ The earliest signs are usually conduction system abnormalities, such as right bundle branch block, with or without multifocal ventricular extrasystoles. Over time, higher-grade conduction system dysfunctions and ventricular arrhythmias can also occur. Sudden death is a common complication. ${ }^{4}$ Late-stage disease typically features dilated cardiomyopathy and congestive heart failure. A smaller proportion of patients with chronic Chagas disease have the digestive form (with or without cardiac involvement). The digestive form of Chagas disease ranges from mild motility disorders to mega syndromes, most commonly involving the esophagus and/or colon. ${ }^{5}$

The immunologic, physiologic, and pathologic mechanisms of chronic Chagas disease are complex. ${ }^{6}$ Serologic testing often shows discordant results, current treatment requires the use of toxic drugs with suboptimal efficacy in chronic infection, and no vaccines for Chagas disease currently exist. It is clear that better diagnostic, preventive, and therapeutic options are urgently needed. ${ }^{7}$ An experimental animal model that closely mimics the chronic manifestations of Chagas heart disease in humans would provide a valuable tool in efforts to develop new diagnostic tests, drugs, and vaccines.

Many mammal species are susceptible to infection by T. cruzi, including mice, ${ }^{8-10}$ rats, ${ }^{11-13}$ hamsters, ${ }^{14,15}$ pigs, ${ }^{16-19}$ dogs, ${ }^{14,16,20}$ and primates. ${ }^{21,22}$ In mice, the species most frequently used for experimental $T$. cruzi infection, clinical manifestations vary depending on the lineage of the animal and the strain of the parasite..$^{23-25}$ Nonhuman primates experience a spectrum of disease similar to that in humans, but only after years of infection; in a rhesus monkey model, chronic conduction system abnormalities were demonstrated 15 to 17 years after infection. ${ }^{22}$ In addition, primates require extensive resources and infrastructure for housing, maintenance, and handling.

The guinea pig is an important natural $T$. cruzi reservoir host in Peru ${ }^{26-29}$ and Bolivia. ${ }^{30,31}$ Guinea pigs are raised in large numbers by Andean residents as a source of meat and household income. The animals are normally housed close to or inside human dwellings and constitute an important blood meal source for domestic vectors such as Triatoma infestans. Based on the observation of cardiac lesions in four naturally infected guinea pigs (Cavia porcellus) at 6 to 9 months of age, ${ }^{32}$ we hypothesized that guinea pigs would provide a practical infection model that might develop disease in a shorter period than nonhuman primates. The few published studies of experimental infection in guinea pigs have studied small numbers of animals and generally have focused on the acute phase. ${ }^{33-35}$ The present study evaluates parasitologic, immunologic, and histopathologic aspects of experimental infection with $T$. cruzi ( $Y$ strain) in C. porcellus at multiple points in time until 365 days after inoculation.

\section{Materials and Methods}

\section{Parasites}

Trypomastigotes of T. cruzi (Y strain) were donated by Dr. Eufrosina Umezawa (Instituto de Medicina Tropical, Universidade de São Paulo, São Paulo, Brazil). The strain was maintained in an in vitro culture using LLC-MK ${ }_{2}$ cells according to published procedures. ${ }^{36}$ The parasites were collected from the culture supernatant in RPMI 1640 medium (Sigma-Aldrich, St. Louis, MO) and were counted using a Neubauer chamber.

\section{Animals}

We used 90 female Andean guinea pigs, each 2 months old and weighing 600 to $700 \mathrm{~g}$. The animals were sourced from the Pachacamac region of Lima, an area without vector-borne transmission of $T$. cruzi. Before parasite inoculation, blood samples were taken from each animal by cephalic or saphenous venipuncture. The sera were tested for the presence of anti-T. cruzi antibodies using the enzyme-linked immunosorbent assay (ELISA) described later herein and also for detection of $T$. cruzi DNA by PCR, and all the animals used in this study were negative for both tests.

\section{Experimental Infections}

Seventy-two guinea pigs were injected with $10^{4}$ parasites in $100 \mu \mathrm{L}$ of RPMI 1640 medium intradermally in the dorsal lumbar region (experimental group). Eighteen guinea pigs were injected intradermally with $100 \mu \mathrm{L}$ of RPMI 1640 medium alone (control group). The protocol was approved by the San Marcos University Animal Use and Welfare Committee. All the experiments adhered to the Guidelines for Animal Experimentation of the Universidad Nacional Mayor de San Marcos.

\section{Preparation of Tissue Samples}

Eight animals from the experimental group and two from the control group were sacrificed at each of the following time points: $5,15,20,25,40,55,115,165$, and 365 days after inoculation. Tissue samples (heart, intestine, liver, lung, skeletal muscle, kidney, brain, skin, esophagus, and spleen) were fixed in absolute ethanol and in 10\% formalin in PBS. Blood and serum samples from each animal were obtained immediately before sacrifice and were stored at $-20^{\circ} \mathrm{C}$ until use.

\section{Detection of Parasitemia by Microhematocrit}

On the day of sacrifice, a $50-\mu \mathrm{L}$ specimen of blood from each animal was collected in a heparinized capillary tube. The tubes were centrifuged at $900 \times g$ for 5 minutes, and the buffy coat was extracted and spread on a slide. The slides were examined by light microscopy to detect the parasites in all fields. The number of parasites encountered was expressed in terms of parasites per milliliter of blood. 


\section{ELISA Test for Detection of IgM and IgG to}

\section{T. cruzi}

The kinetics for the production of IgM and IgG to T. cruzi were measured by trypomastigote excreted-secreted antigens (TESA)-ELISA, as described previously. ${ }^{37}$ Briefly, ELISA 96-well plates (Immulon 2; Thermo Labsystems, Franklin, MA) were coated with $2 \mu \mathrm{g} / \mathrm{mL}$ of TESA and were incubated with guinea pig serum, 1:100 dilution (IgG detection) or 1:50 dilution (IgM detection). Horseradish peroxidase conjugate was used in a 1:5000 dilution of goat anti-guinea pig IgG (KPL Inc., Gaithersburg, $\mathrm{MD}$ ) or in a 1:2500 dilution of goat anti-guinea pig IgM (Nordic Immunological Laboratories, Tilburg, the Netherlands). Next, the plates were incubated with $0.1 \mathrm{mg}$ per well of o-phenylenediamine dihydrochloride (Sigma-Aldrich) and $0.05 \% \mathrm{H}_{2} \mathrm{O}_{2}$. Optical density was determined at $495 \mathrm{~nm}$ using a VersaMax microplate spectrophotometer (Molecular Devices Inc., Sunnyvale, CA). Each serum sample was analyzed in duplicate.

\section{Western Blot Analysis}

The TESA blot was performed as described by Umezawa et al. ${ }^{38}$ We used a 1:100 dilution of serum samples and a 1:4000 dilution of horseradish peroxidase-conjugated goat anti-guinea pig IgG (KPL Inc.) or a 1:250 dilution of goat anti-guinea pig IgM (Nordic Immunological Laboratories). In this method, two band patterns can be identified. In the case of the TESA antigen from the $Y$ strain of T. cruzi, the band patterns are six bands in a ladder at 130 to $160 \mathrm{kDa}$ designated as shed acute-phase antigen (SAPA) bands and a broad antigen band at 150 to 160 $\mathrm{kDa}$. The SAPA bands represent the major surface antigens of trypomastigotes and serve as an indicator of acute infection. The $150-$ to $160-\mathrm{kDa}$ band is a diagnostic indicator of chronic T. cruzi infection. ${ }^{38}$

\section{DNA Extraction and PCR}

DNA was purified by proteinase $\mathrm{K}$ digestion (Invitrogen, Carlsbad, CA) and phenol-chloroform extraction from $500 \mu \mathrm{L}$ of clot or $25 \mathrm{mg}$ of tissue samples. The extracted DNA was resuspended in $100 \mu \mathrm{L}$ of $10 \mathrm{mmol} / \mathrm{L}$ Tris- $\mathrm{HCl}$, $1 \mathrm{mmol} / \mathrm{L}$ EDTA. ${ }^{39}$ A PCR targeting the kinetoplast DNA of $T$. cruzi was performed as previously described using primers 121 (5'-AAATAATGTACGGGKGAGATGCATGA$\left.3^{\prime}\right)$ and 122 (5'-GGTTCGATTGGGGTTGGTGTAATATA$\left.3^{\prime}\right) 4^{40,41}$ We included internal control primers that amplify a 71-bp fragment. This fragment corresponds to multicopy nuclear DNA short interspersed element that is specific to guinea pigs. ${ }^{42}$ Specimens showing the characteristic 330-bp minicircle amplification product were considered positive; those with the 71-bp band (short interspersed elements) but no 330-bp band were considered negative. The PCR was considered negative after three DNA extractions and two amplifications of each extraction were found to be negative.

\section{Histopathologic Analysis}

Tissue samples from eight animals from the infected group and two animals from the control group were collected at each time point. The tissue samples were prepared in 10\% formalin-PBS and embedded in paraffin. Two 4- $\mu \mathrm{m}$ sections from all the tissue samples were prepared for each animal and were stained with H\&E. Two additional sections of each cardiac specimen were stained with Masson's trichrome. All the sections were approximately equal in size.

Inflammatory infiltrate was classified semiquantitatively: 1, absent; 2, focal or mild myocarditis (lymphocytes seen in $2 \%$ to $15 \%$ of the entire section); 3 , moderate (lymphocytes seen in $20 \%$ to $60 \%$ of the section); and 4 , severe myocarditis (lymphocytes seen in $>70 \%$ of the section). Mild myocarditis was focal; moderate and severe inflammation was either multifocal or diffuse. The quantification of parasites was based on the mean number of amastigotes seen in the entirety of the two examined sections: absent (0 parasites seen), rare (one amastigote nest), moderate (2 to 10 nests), or abundant (>10 nests). Other pathologic changes, such as vasculitis, necrosis, and fibrosis, were observed.

\section{Statistical Methods}

Multivariable linear regression was used to relate the degree of cardiac inflammation to the abundance of amastigote nests in the heart, adjusted for time in days after infection and parasitemia by microhematocrit. STATA version 10 (StataCorp LP, College Station, TX) and SAS version 9.2 (SAS Institute Inc., Chicago, IL) were used for the statistical analyses. Because the degree of inflammation rose during the acute phase and fell later in the course of the infection, the variable for time after infection was included as a quadratic function in the regression model.

\section{Results}

\section{Infection Dynamics}

We observed several distinct phases based on the kinetics of the parasitemia, the serum antibody response, and the occurrence of pathologic changes. The prepatent period corresponded to the initial period before the first observation of parasites in blood 15 days after inoculation (Figure 1). During the acute phase (15 to 55 days after inoculation), parasites were observed by microscopy in blood, and anti-T. cruzi IgM antibodies were demonstrable. The peak parasitemia levels occurred 20 days after inoculation and coincided with peak $\operatorname{lgM}$ and the first appearance of anti-T. cruzi IgG antibodies. The early chronic phase, 115 to 165 days after inoculation, was defined by the disappearance of microscopically detectable parasitemia, the presence of anti-T. cruzi IgG antibody, and limited histopathologic changes. Finally, the chronic phase (365 days after inoculation) was characterized by significant histopathologic changes. No 


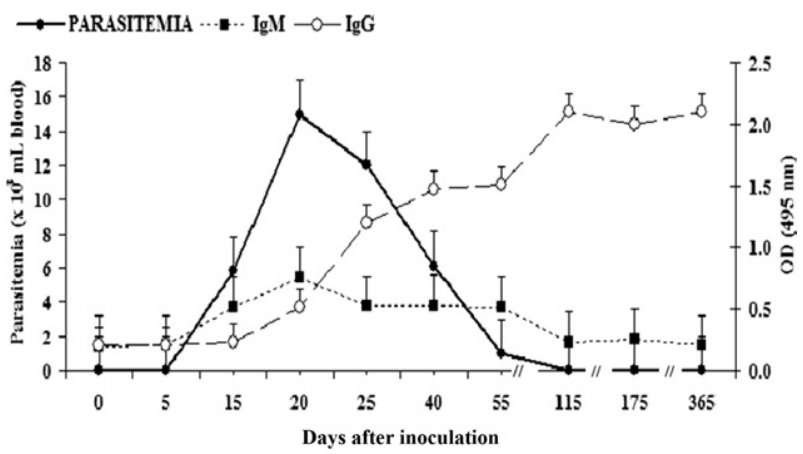

Figure 1. Detection of parasitemia using the microhematocrit technique and IgM and IgG to T. cruzi by TESA-ELISA during experimental T. cruzi infection of $C$. porcellus. Eight animals were used per group. The points and error bars represent median $\pm \mathrm{SE}$.

spontaneous deaths or gross pathologic changes were observed by the time of necropsy.

Serum IgM and IgG antibodies against T. cruzi SAPA bands were detected at multiple time points during acute infection in all infected animals (Figure 2). Forty to 55 days after inoculation, IgM that recognizes the complex of $150-$ to $160-\mathrm{kDa}$ proteins associated with chronic infection was also detected (Figure 2A). Specific IgG antibodies to the 150- to $160-\mathrm{kDa}$ proteins were detected beginning day 40 after inoculation and continued to be observed until the end of the experiment (Figure 2B).

\section{Histologic Analysis of Infected Tissue}

Tissue sections collected at each time point were stained with H\&E. Two additional cardiac tissue sections per animal at each time point were stained with Masson's trichrome. In the acute phase of the infection $(n=48)$, amastigote nests were seen from day 15 after inoculation

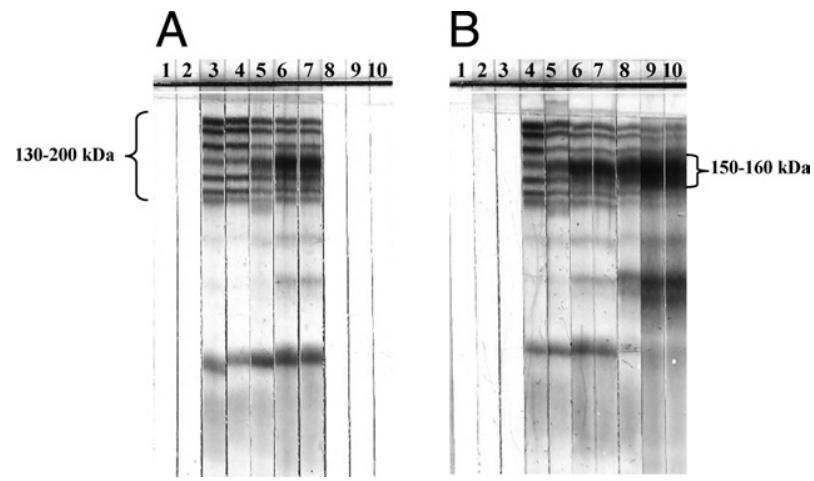

Figure 2. Detection of IgM and IgG by TESA blot analysis during experimental T. cruzi infection of C. porcellus. A: IgM detection. The classic six SAPA bands ( 130 to $200 \mathrm{kDa}$ ) were seen during the acute phase (until 55 days after inoculation). The bottom band is slightly smeared due to prolonged run time. On day 55 after inoculation, a single 150- to $160-\mathrm{kDa}$ band was also detected. From 115 days after inoculation until the end of the experiment, IgM was undetectable. B: IgG detection. SAPA bands (130 to $200 \mathrm{kDa}$ ) were observed from 20 until 25 days after inoculation. Subsequently, the 150- to 160-kDa band was also detected until the end of the experiment. Lane 1: day 0 (before experimental inoculation). Serum samples of guinea pig after inoculation: lane 2, day 5 ; lane $\mathbf{3}$, day $\mathbf{1 5}$; lane $\mathbf{4}$, day 20; lane $\mathbf{5}$, day $\mathbf{2 5}$ lane 6, day 40; lane 7, day 55; lane 8, day 115 ; lane 9, day 165; and lane 10, day 365 .

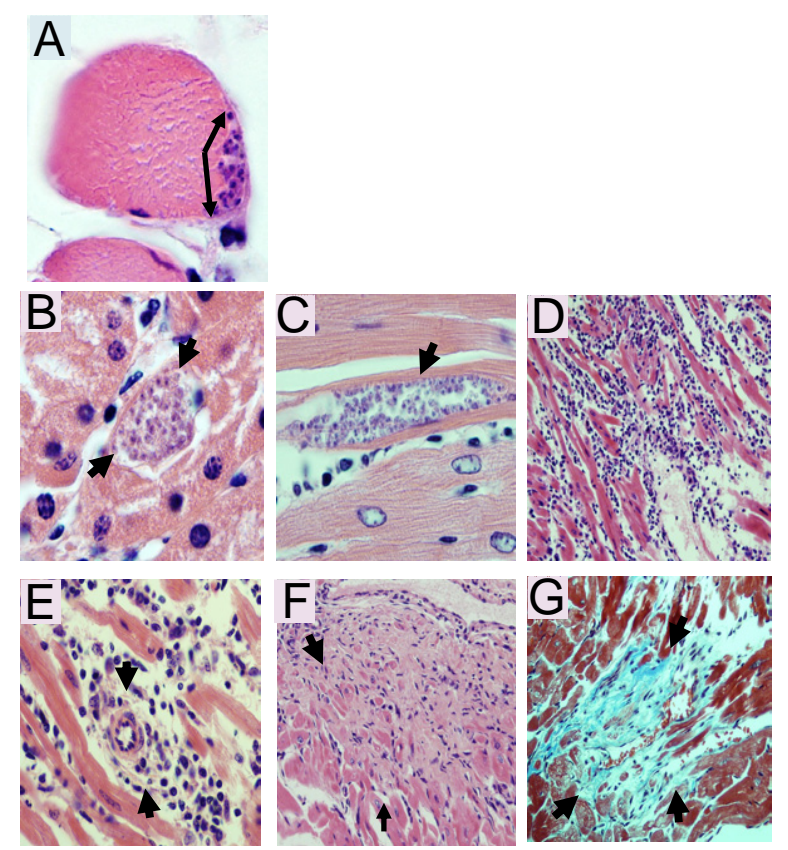

Figure 3. Histopathologic analysis in C. porcellus after inoculation of $T$. cruzi strain Y. Amastigote nests (arrows) were seen 25 days after inoculation in skeletal muscle $(\mathbf{A})$ and kidney $(\mathbf{B})$. Original magnification: $\times 1000$. Histopathologic analysis in cardiac tissue demonstrates amastigote nests (arrow) between myocardial fibers 25 days after inoculation $(\mathbf{C})$; severe and diffuse inflammatory infiltrate 25 days after inoculation (D); perivascular inflammation (arrows) 25 days after inoculation (E); areas of necrosis 56 days after inoculation (F); and foci of interstitial fibrosis (arrows) and lymphocytic infiltrate (arrows) 365 days after inoculation (G). Original magnification: $\times 1000(\mathbf{C}) ; \times 200(\mathbf{D}, \mathbf{F}$, and $\mathbf{G}) ; \times 500(\mathbf{E})$. Staining: H\&E $(\mathbf{A}-\mathbf{F})$; Masson's trichrome $(\mathbf{G})$.

in many types of tissues, including skeletal muscle (20\%) (Figure 3A), kidney (25\%) (Figure 3B), brain (25\%), liver (12.5\%), and intestine (10\%). During the chronic phase of the infection $(n=24)$, amastigote nests were seen in the kidney $(20.8 \%)$, skeletal muscle $(12.5 \%)$, brain $(8.3 \%)$, liver $(4.16 \%)$, and intestine $(4.16 \%)$. Heart muscle was the most affected tissue, with $>50 \%$ of cardiac sections showing amastigote nests from day 20 after inoculation. Amastigotes were observed between cardiac fibers and were surrounded with lymphocytes (Figure 3C). All animals examined 25 days after inoculation had abundant parasites in cardiac tissue. In addition, amastigote nests in cardiac tissue were particularly common in the chronic phase, with $60 \%$ to $90 \%$ of animals that were examined showing rare to moderate parasites visualized 115, 155, and 365 days after inoculation (Figure 4). In noncardiac tissues, amastigote nests were generally sparse, with mild or absent inflammation; therefore, histologic analysis was restricted to cardiac tissue.

Inflammatory infiltrates (predominantly lymphocytes with polymorphonuclear cells) were seen in $73 \%$ of cardiac tissue sections from infected animals. In general, however, the areas of inflammation were not visibly colocalized with parasite nests (Figure 3D). Nevertheless, in a multivariable linear regression model adjusted for days after inoculation and peripheral blood parasitemia level, the degree of inflammation was strongly predicted by the number of amastigote nests $\left(R^{2}=0.29 ; P=0.006\right)$. The peak number of amastigote nests (mean \pm SD, $41 \pm$ 


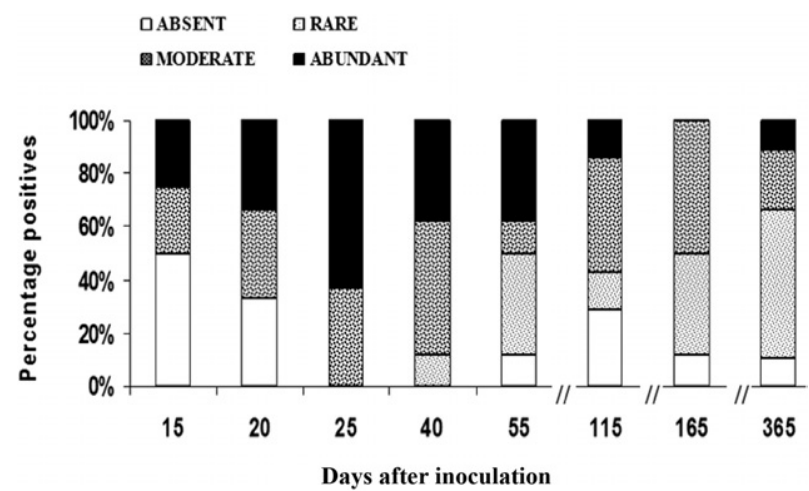

Figure 4. Percentage of animals that presented rare, moderate, or abundant amastigote nests in cardiac tissue of C. porcellus during experimental infection by T. cruzi. Quantification of parasite number was the mean number of parasites seen in two entire sections: rare, 1 nest; moderate, 2 to 10 nests; abundant, $>10$ nests. H\&E stain. Eight animals per group.

23.6) and the highest degree of inflammation (38\% moderate and $62 \%$ severe) were observed 25 days after inoculation (Figures 3D, 4, and 5). Vasculitis was prominent 20 to 25 days after inoculation (Figures $3 E$ and 6), followed by the appearance of necrosis 40 to 55 days after inoculation (Figures $3 \mathrm{~F}$ and 6). At 365 days after inoculation, $62 \%$ of infected animals had cardiac fibrosis (Figures 3G and 6). Fibrotic areas were associated with lymphocytic inflammatory infiltrates (Figure 3G).

\section{Tissue Distribution of T. cruzi DNA by Conventional PCR}

During the acute infection, T. cruzi kinetoplast DNA was detected in peripheral blood in $100 \%$ of the animals. The percentage of guinea pigs with positive results by PCR in blood decreased to $43.75 \%$ (7 of 16 ) in the early chronic phase and to $37.5 \%$ (3 of 8 ) 365 days after inoculation (Figure 7).

The proportion of positive results by PCR in intestine, liver, lung, skeletal muscle, kidney, brain, skin, esopha-

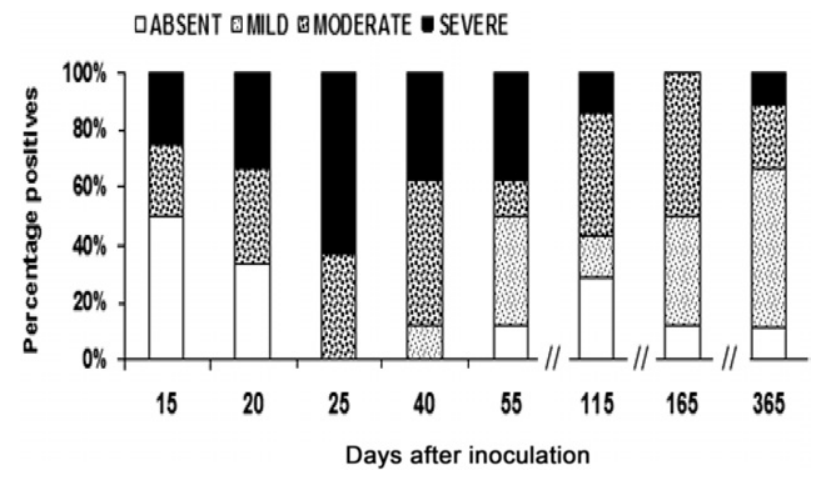

Figure 5. Percentage of animals that presented mild, moderate, or severe inflammation in cardiac tissue of C. porcellus during experimental T. cruzi infection. Semiquantitative analysis of the degree of inflammation was evaluated in two entire sections: mild, lymphocytes in $2 \%$ to $15 \%$ of the entire section with focal distribution; moderate, lymphocytes in $20 \%$ to $60 \%$ of the entire section; severe, lymphocytes in $>70 \%$ of the entire section. For moderate and severe inflammation, the distribution was either multifocal or diffuse. H\&E stain. Eight animals per group.

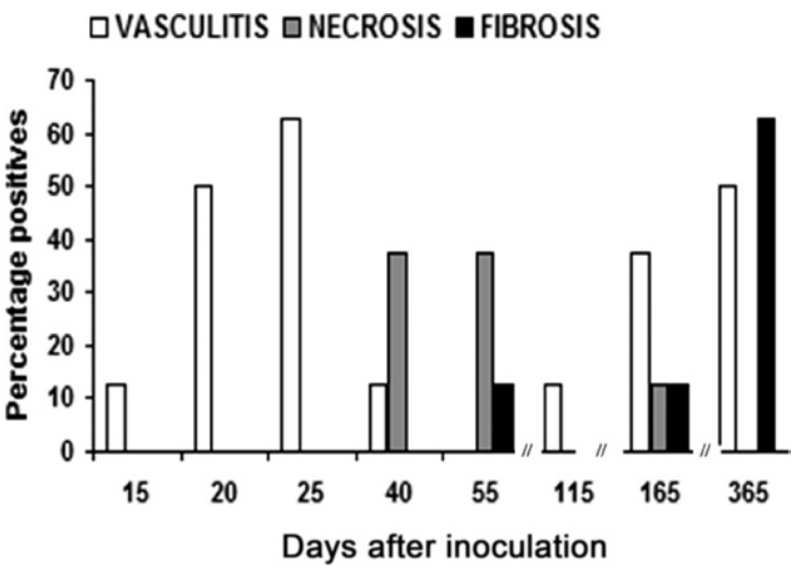

Figure 6. Percentage of animals that presented vasculitis, necrosis, and fibrosis in cardiac tissue of $C$. porcellus during experimental infection by $T$. cruzi. Qualitative analysis was evaluated in two total sections. H\&E or Masson's trichrome stain. Eight animals per group.

gus, and spleen tissue is shown in Figure 7. DNA from $T$. cruzi was detected in all tissues during the acute infection in at least some guinea pigs; however, the prevalence decreased in each tissue type during the early chronic and late chronic phases. At 365 days after inoculation, $\mathrm{PCR}$ results were negative for all specimens of the skin, esophagus, and lung. Throughout the infection, the highest percentage of positive results by PCR occurred in cardiac tissue, ranging from $100 \%$ in the acute phase to $75 \%$ at 365 days after inoculation.

\section{Discussion}

Chagas disease continues to be a major cause of morbidity and mortality in endemic countries of Latin America. ${ }^{2}$ The lifelong nature of the infection, its complex pathogenesis, and the limited efficacy and high toxicity of antitrypanosomal drugs pose challenges to clinicians and researchers. ${ }^{6}$ Less than $30 \%$ of T. cruzi-infected individuals develop clinical disease, the manifestations are heterogeneous, and onset typically occurs decades after the initial infection. Natural history studies cannot be conducted in humans because progression typically occurs over decades, and $T$. cruzi infections that are detected in the acute and early chronic phases should be treated. Animal models, therefore, take center stage in studying the pathogenesis and progression of Chagas disease.

The present study provides strong support for the use of guinea pigs as a model for the pathology of Chagas disease. The natural history of the infection in this guinea pig model includes a typical acute phase with high parasitemia, parasite invasion of multiple tissue types, and anti- $T$. cruzi antibodies. Among these were IgM and IgG antibodies recognizing the SAPA, derived from the $T$. cruzi trans-sialidase family, which act as indicators of acute human infection. ${ }^{38}$ The onset of the early chronic phase coincided with the loss of IgM antibodies, the disappearance of parasites from the blood and from most tissue, and the appearance of amastigote nests in the 


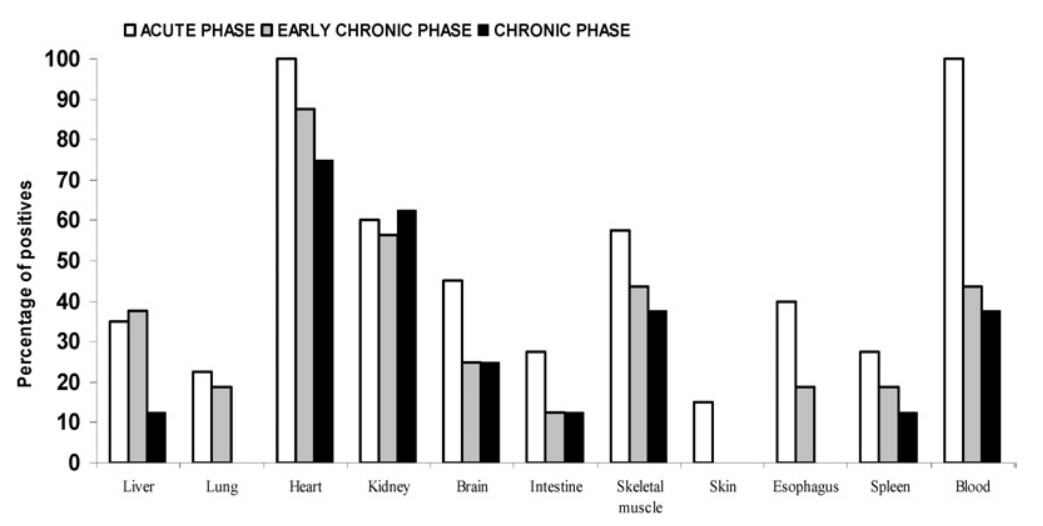

Figure 7. Detection of kinetoplast DNA by PCR in blood and tissue samples during experimental infection of C. por cellus by T. cruzi. Acute phase: 5 to 55 days after inoculation. $n=40$ animals. Early chronic phase: 115 to 165 days after inoculation. $n=16$ animals. Chronic phase: 365 days after inoculation. $n=8$ animals.

cardiac tissue, similar to what is observed in human infection.

In human patients, the indeterminate form of chronic Chagas disease, which is nearly universal in the early chronic phase, can last for 15 to 30 years or for the life of the host. The early chronic phase may be attributed to a progressive stage in the life of the parasite that ends with chronic disease manifestations ${ }^{43}$ or may be the result of host-parasite equilibrium. ${ }^{44}$ Understanding the mechanisms involved in maintenance of the indeterminate form may be important in explaining the eventual progression to clinical disease in a portion of infected individuals. Dogs $^{43}$ and nonhuman primates ${ }^{44}$ have been shown to have an early chronic phase with characteristics similar to humans; however, development of the disease in these animals occurs over a long period. The development of the early chronic phase of disease in guinea pigs occurs in a much shorter period, making this animal model practical for laboratory research.

Mouse models are the most frequently used animal for experimental models of Chagas disease and have proved to be extremely useful. ${ }^{8-10}$ A broad range of standardized reagents is available to study this infection in mice. The clinical profile of inbred mouse strains is highly predictable, which has advantages and disadvantages. In many respects, however, mouse models do not adequately represent the chronic phase of Chagas disease. Some combinations of mouse lineage and parasite strain show high, even universal, acute lethality. ${ }^{23,24}$ In some mouse model systems, unlike in human disease, a broad range of organs are affected even in the chronic phase. ${ }^{45,46}$ Rats also develop intense myocarditis and parasite nests in the tissue during the acute phase, with regression of inflammation, fibrosis, and cardiomyopathy in the chronic phase. ${ }^{47}$

The guinea pig model may have some contrasting advantages. Similar to humans with the disease, almost all infected guinea pigs survive the acute phase, the development of chronic pathologic abnormalities is frequent but not universal, and the heart is by far the most affected organ. A potential advantage of guinea pigs over rats or mice is the ability to collect larger volumes of urine and blood without sacrificing the animal. ${ }^{48}$ The fact that the guinea pig is an important natural reservoir host in Andean regions may allow appropriate testing of the virulence and chronic pathogenicity of local T. cruzi strains compared with the standard laboratory $Y$ strain that we used in this first model. Adaptation of strains to their natural hosts has been well-demonstrated in North America and may have implications for levels of pathogenicity and local transmission dynamics. ${ }^{49} T$. cruzi has been shown to infect adipose tissue, $^{8}$ and rapid increases in the prevalence of obesity and metabolic syndrome in Latin America raise the question of how these factors may interact with Chagas cardiomyopathy. ${ }^{50}$ Guinea pigs show a distribution of visceral adipose tissue (eg, epicardial and perirenal fat) similar to that of humans, which may facilitate their use as a model for this interaction. ${ }^{51}$

Finally, we observed congenital $T$. cruzi transmission in a few experimentally infected guinea pigs (R.H. Gilman, unpublished data). Because this species shares with humans the hemochorial placental type and a homologous process of trophoblast invasion, ${ }^{52,53}$ C. porcellus may be an excellent species in which to develop an experimental model for congenital Chagas disease.

The present studies represent the first systematic, comprehensive study of the guinea pig as a model of $T$. cruzi infection, measuring blood and tissue parasitism and tissue pathology up to 1 year after infection. These results suggest that use of this model has the potential to advance Chagas disease research on several fronts. Although the frequency of cardiac involvement in the guinea pigs in this study $(62.5 \%)$ was higher than that in infected humans who develop clinical pathology (20\% to $30 \%$ ), the spectral nature of the disease in guinea pigs may allow for analysis of predictors of disease progression. Parasites do not consistently persist in cardiac tissue in many mouse models, ${ }^{54,55}$ making the heart tropism observed in guinea pigs relatively unusual and informative. Furthermore, heart failure in the guinea pig model parallels the human pathogenesis in terms of changes in calcium cycling, myosin isoforms, and myocardial function. ${ }^{56}$ In the present model, vasculitis in the capillaries was an important feature in the acute and chronic phases. This vasculopathy is manifest in humans and animals by vasospasm, reduced blood flow, focal ischemia, platelet thrombi, increased platelet aggregation, and elevated plasma levels of thromboxane $A_{2}$ and endothelin-1. ${ }^{57-59}$ These findings indicate the possibility of using the guinea pig to examine this novel aspect of Chagas cardiac pathogenesis. The guinea pig model has 
already been used for the testing of vaccines for $T$. cruzi and other infections. ${ }^{60-62}$ The guinea pig model might also be useful for drug testing, with the possibility of following cohorts of treated and untreated guinea pigs for development and progression of cardiac abnormalities, similar to the design of the ongoing benznidazole trial for chronic Chagas disease in humans. ${ }^{63}$

No gastrointestinal disease was observed in the guinea pigs used in this study. However, only a few patients with clinical Chagas disease have digestive involvement. ${ }^{64}$ Because only eight animals were sacrificed at each time point, it is possible that too few guinea pigs were used to detect the rare occurrences of gastrointestinal disease. Other disadvantages of the guinea pig model include the fact that the guinea pig genome has not been fully elucidated and that they are not ideal for genetic manipulation. ${ }^{65}$ Currently, few tools are available to examine immune correlates of disease progression and drug efficacy in guinea pigs compared with those available for mice. The development of more extensive immunologic tools will be an important next step in establishing the guinea pig as a comprehensive model of $T$. cruzi infection. We anticipate that the reemergence of guinea pigs as models of human pathogens will facilitate this effort. ${ }^{63}$ Nevertheless, the present data demonstrate that $T$. cruzi infection of guinea pigs recapitulates human pathology and provide a solid foundation for the use of these natural reservoirs of $T$. cruzi infection as laboratory models of Chagas disease.

\section{Acknowledgments}

We thank Henry Bishop for taking photographs of tissue slides, Allen Hightower for statistical advice, Edith Malaga and Juan Pacori for technical assistance, and Pablo S. Esquives for administrative assistance.

\section{References}

1. Organización Panamericana de la Salud: Estimación cuantitativa de la enfermedad de Chagas en las Américas. Montevideo, Uruguay, Organización Panamericana de la Salud, 2006

2. Prata A: Clinical and epidemiological aspects of Chagas disease. Lancet Infect Dis 2001, 1:92-100

3. Rassi A Jr, Rassi A, Little WC: Chagas' heart disease. Clin Cardiol 2000, 23:883-889

4. Rassi A Jr, Rassi SG, Rassi A: Sudden death in Chagas' disease. Arq Bras Cardiol 2001, 76:75-96

5. de Oliveira RB, Troncon LE, Dantas RO, Menghelli UG: Gastrointestinal manifestations of Chagas' disease. Am J Gastroenterol 1998 93:884-889

6. Marin-Neto JA, Cunha-Neto E, Maciel BC, Simoes MV: Pathogenesis of chronic Chagas heart disease. Circulation 2007, 115:1109-1123

7. Tarleton RL, Reithinger R, Urbina JA, Kitron U, Gürtler RE: The challenges of Chagas Disease: grim outlook or glimmer of hope. PLoS Med 2007, 4:e332

8. Guarner J, Bartlett J, Zaki SR, Colley DG, Grijalva MJ, Powell MR: Mouse model for Chagas disease: immunohistochemical distribution of different stages of Trypanosoma cruzi in tissues throughout infection. Am J Trop Med Hyg 2001, 65:152-158

9. Rodriguez AM, Aragort De Rossell R, De Jesus R, Calcagno M, Maizo De Segnini Z, Segnini S, Diaz S: Blood and culture trypomastigotes forms of Trypanosoma cruzi Y I.- Difference on the infectivity in Balb/C mice. Parasitología al día 2000, 24:12-21
10. Aragort De Rossell R, Rodriguez AM, De Jesus R, Calcagno M, Maizo De Segnini Z, Diaz S: Blood and culture trypomastigotes forms of Trypanosoma cruzi Y: II pathology of Chagas disease in Balb/c mice. Parasitología al día 2000, 24:79-87

11. Galuppo S, Bacigalupo A, García A, Ortiz S, Coronado X, Cattan PE, Solari A: Predominance of Trypanosoma cruzi genotypes in two reservoirs infected by sylvatic Triatoma infestans of an endemic area of Chile. Acta Trop 2009, 111:90-93

12. Blandon R, Leandro IM, Johnson CM: Clinical, electrocardiographic and angiographic evaluation of natural reservoirs of Chagas' disease in the Republic of Panama. Rev Med Panama 1995, 20:108-115

13. RoffÊ E, Oliveira F, Souza AL, Pinho V, Souza DG, Souza PR, Russo RC, Santiago HC, Romanha AJ, Tanowitz HB, Valenzuela JG, Teixeira MM: Role of CCL3/MIP-1alpha and CCL5/RANTES during acute Trypanosoma cruzi infection in rats. Microbes Infect 2010, 12:669-676

14. Bilate AM, Teixeira PC, Ribeiro SP, Brito T, Silva AM, Russo M, Kalil J, Cunha-Neto E: Distinct outcomes of Trypanosoma cruzi infection in hamsters are related to myocardial parasitism, cytokine/chemokine gene expression, and protein expression profile. J Infect Dis 2008, 198:614-623

15. Colmanetti FH, Teixeira Vde P, Rodrigues ML, Chica JE, Reis MG dos Santos VM: Myocardiocyte ultrastructure and morphometrical analysis in hamsters experimentally infected with Trypanosoma cruzi. Ultrastruct Pathol 2005, 29:139-147

16. Fujita O, Sanabria L, Inchaustti A, De Arias AR, Tomizawa Y, Oku Y: Animal reservoirs for Trypanosoma cruzi infection in an endemic area in Paraguay. J Vet Med Sci 1994, 56:305-308

17. Valente VC, Valente S, Noireau F, Carrasco H, Miles A: Chagas disease in the Amazon basin: association of Panstrongylus geniculatus (Hemiptera: reduviidae) with domestic pigs. J Med Entomol 1998, 35:99-103

18. Valente V: Potential for domestication of Panstrongylus geniculatus (Latreille, 1811) (Liemiptera, reduviidae, triatominae) in the municipality of Muaná, Marajó Island, state of Pará, Brazil. Mem Inst Oswaldo Cruz 1999, 94(Suppl 1): 399-400

19. Salazar-Schettino PM, Bucio MI, Cabrera M, Bautista J: First case of natural infection in pigs: review of Trypanosoma cruzi reservoirs in Mexico. Mem Inst Oswaldo Cruz 1997, 92:499-502

20. Cruz-Chan JV, Bolio-Gonzalez M, Colin-Flores R, Ramirez-Sierra MJ, Quijano-Hernandez I, Dumonteil E: Immunopathology of natural infection with Trypanosoma cruzi in dogs. Vet Parasitol 2009, 162:151-155

21. Pung OJ, Hulsebos LH, Kuhn RE: Experimental Chagas' disease (Trypanosoma cruzi) in the Brazilian squirrel monkey (Saimiri sciureus): hematology, cardiology, cellular and humoral immune responses. Int J Parasitol 1988, 18:115-120

22. Carvalho CM, Andrade MC, Xavier SS, Mangia RH, Britto CC, Jansen AM, Fernandes O, Lannes-Vieira J, Bonecini-Almeida MG: Chronic Chagas' disease in rhesus monkeys (Macaca mulatta): evaluation of parasitemia, serology, electrocardiography, echocardiography, and radiology. Am J Trop Med Hyg 2003, 68:683-691

23. Andrade SG, Andrade V, Brodskyn C, Magalhaes JB, Barral-Neto M: Immunological response of Swiss mice to infection with different strains of Trypanosoma cruzi. Ann Trop Med Parasitol 1985, 79:397-407

24. Melo RC, Brener Z: Tissue tropism of different Trypanosoma cruzi strains. J Parasitol 1978, 64:475-482

25. Andrade LO, Machado CR, Chiari E, Pena SD, Macedo AM: Trypanosoma cruzi: role of host genetic background in the differential tissue distribution of parasite clonal populations. Exp Parasitol 2002, 100: 269-275

26. Herrer A: Trypanosomiasis americana en el Perú, III: importancia del cobayo como reservorio de la enfermedad de Chagas en la región sudoccidental. Rev Perú Med Exp Salud Pública 1955, 9:1-2

27. Acosta HM, Ferreira CS, de Carvalho ME: Human infection with Trypanosoma cruzi in Nasca, Peru: a seroepidemiological survey. Rev Inst Med Trop Sao Paulo 1997, 39:107-112

28. Cordova E: Investigation of Chagas' disease in Peru: epidemiological study in the Tambo valley (Matalaque district, Department of Moquegua), I: preliminary observations, 1958-1959. Bol Chil Parasitol 1961, 16:54-59

29. Levy MZ, Bowman NM, Kawai V, Waller L, Cornejo JG, Cordova E, Gilman R, Bern C: Periurban Trypanosoma cruzi infected Triatoma infestans: Arequipa, Peru. Emerg Infect Dis 2006, 12:1345-1352 
30. Secretaria Nacional de Salud-Bolivia: Programa Nacional de Control de Chagas. La Paz, Bolivia, Ministerio de Desarrollo Humano/Secretaría Nacional de Salud, 1994

31. Albarracin-Veizaga $H$, Carvalho $M$, Nascimento $E$, Rodrigues L, Casanova C, Barata JS: Chagas disease in an area of recent occupation in Cochabamba. Bolivia Rev Saúde Pública 1999, 33:230-236

32. Milei J, Scordo D, Basombrio MA, Beigelman R, Storino R: Myocardial involvement in Cavia porcellus naturally infected with Trypanosoma cruzi. Medicina (B Aires) 1989, 49:315-319

33. Pérez Brandán C, Padilla AM, Diosque P, Basombrío MA: Trypanosoma cruzi: infectivity modulation of a clone after passages through different hosts. Exp Parasitol 2006, 114:89-93

34. Dalmasso AP, Jarvinen JA: Experimental Chagas' disease in complement-deficient mice and guinea pigs. Infect Immun 1980, 28 : 434-40

35. Nargis M, Chisty M, Ihama $Y$, Sato H, Inaba T, Kamiya H: Kinetics of Trypanosoma cruzi infection in guinea-pigs, with special reference to the involvement of epidermal Langerhans' cells in the induction of immunity. Parasitology 2001, 123:373-380

36. Jazin EE, Luquetti AO, Rassi A, Frasch ACC: Shift of excretorysecretory immunogens of Trypanosoma cruzi during human Chagas' disease. Infect Immun 1991, 59:2189-2191

37. Umezawa ES, Nascimento MS, Stolf AMS: Enzyme-linked immunosorbent assay with Trypanosoma cruzi excreted-secreted antigens (TESA-ELISA) for serodiagnosis of acute and chronic Chagas' disease. Diagn Microbiol Infect Dis 2001, 39:169-176

38. Umezawa ES, Nascimento M, Kesper N, Coura JR, Borges-Pereira J, Junqueira A, Camargo ME: Immunoblot assay using excreted-secreted antigens of Trypanosoma cruzi in serodiagnosis of congenital, acute, and chronic Chagas' disease. J Clin Microbiol 1996, 34:2143-2147

39. Fitzwater S, Calderon M, Lafuente C, Galdos-Cardenas G, Ferrufino L, Verastegui M, Gilman RH, Bern C; Chagas Disease Working Group in Peru and Bolivia: Polymerase chain reaction for chronic Trypanosoma cruzi infection yields higher sensitivity in blood clot than buffy coat or whole blood specimens. Am J Trop Med Hyg 2008, 79:768-770

40. Schijman AG, Altcheh J, Burgos JM, Biancardi M, Bisio M, Levin MJ, Freilij $\mathrm{H}$ : Aetiological treatment of congenital Chagas' disease diagnosed and monitored by the polymerase chain reaction. J Antimicrob Chemother 2003, 52:441-449

41. Wincker P, Britto C, Pereira JB, Cardoso MA, Oelemann W, Morel CM: Use of a simplified polymerase chain reaction procedure to detect Trypanosoma cruzi in blood samples from chronic chagasic patients in a rural endemic area. Am J Trop Med Hyg 1994, 51:771-777

42. Pizarro JC, Lucero D, Stevens L: A method for the identification of guinea pig blood meal in the Chagas disease vector: Triatoma infestans. Kinetoplastid Biol Dis 2007, 6:1-6

43. Andrade ZA, Andrade SG, Sadigursky M, Wenthold RJ, Hilbert SL, Ferrans VJ: The indeterminate phase of Chagas' disease: ultrastructural characterization of cardiac changes in the canine model. Am J Trop Med Hyg 1997, 57:328-336

44. Bonecini-Almeida MG, Galvao-Castro B, Ribeiro MH, Pirmez C, Laranja F: Experimental Chagas disease in rhesus monkeys, I: clinical, parasitologycal, hematological and anatomo-pathological studies in the acute and indeterminate phase of the disease. Mem Inst Oswaldo Cruz 1990, 85:163-171

45. Lenzi HL, Oliveira DN, Lima MT, Gatass CRR: Trypanosoma cruzi: pan infectivity of $\mathrm{CL}$ strain during murine acute infection. Exp Parasitol 1996, 84:16-27

46. MacCabe RE, Meagher S, Mullins B: Trypanosoma cruzi: explant organ cultures from mice with chronic Chagas' disease. Exp Parasitol 1989, 68:462-467

47. Rendón DA, Genes CM, Triana O: Myocardial cellular damage and the activity of the mitochondrial ATP synthase in rats infected with a Colombian strain of Trypanosoma cruzi. Biomedica 2007, 27(Suppl 1):40-49
48. Matsuzawa T, Nakata M, Tsushima M: Feeding and excretion in the Afghan pika (Ochotona rufescens rufescens), a new laboratory animal. Lab Anim 1981, 15:319-322

49. Roellig DM, Yabsley MJ: Infectivity, pathogenicity, and virulence of Trypanosoma cruzi isolates from sylvatic animals and vectors, and domestic dogs from the United States in ICR strain mice and SD strain rats. Am J Trop Med Hyg 2010, 83:519-522

50. Hidron Al, Gilman RH, Justiniano J, Blackstock AJ, Lafuente C, Selum W, Calderon M, Verastegui M, Ferrufino L, Valencia E, Tornheim JA, O'Neal S, Comer R, Galdos-Cardenas G, Bern C; Chagas Disease Working Group in Peru and Bolivia: Chagas cardiomyopathy in the context of the chronic disease transition. PLoS Negl Trop Dis 2010, $4: e 688$

51. Swifka J, Weiss J, Addicks K, Eckel J, Rösen PC: Epicardial fat from guinea pig: a model to study the paracrine network of interactions between epicardial fat and myocardium. Cardiovasc Drugs Ther 2008, 22:107-114

52. Leiser R, Kaufmann P: Placental structure: in a comparative aspect. Exp Clin Endocrinol 1994, 102:122-134

53. Mess A: The guinea pig placenta: model of placental growth dynamics. Placenta 2007, 28:812-815

54. Andrade LO, Machado CR, Chiari E, Pena SD, Macedo AM: Differential tissue distribution of diverse clones of Trypanosoma cruzi in infected mice. Mol Biochem Parasitol 1999, 25]?>; 100163-172

55. Marinho CR, Bucci DZ, Dagli ML, Bastos KR, Grisotto MG, Sardinha LR, Baptista CR, Gonçalves CP, Lima MR, Alvarez JM: Pathology affects different organs in two mouse strains chronically infected by a Trypanosoma cruzi clone: a model for genetic studies of Chagas' disease. Infect Immun 2004, 72:2350-2357

56. Hasenfuss G: Animal models of human cardiovascular disease, heart failure and hypertrophy. Cardiovasc Res 1998, 39:60-76

57. Rossi M: Microvascular changes as a cause of chronic cardiomyopathy in Chagas' disease. Am Heart J 1990, 120:233-236

58. Huang H, Petkova SB, Cohen AW, Bouzahzah B, Chan J, Zhou J-N, Factor SM, Weiss LM, Krishnamachary M, Mukherjee S, Wittner S, Kitsis RN, Pestell RG, Lisanti MP, Albanese C, Tanowitz HB: Activation of transcription factors $\mathrm{AP}-1$ and $\mathrm{NF}-\kappa \mathrm{B}$ in murine Chagasic myocarditis. Infect Immun 2003, 71:2859-2567

59. Tanowitz HB, Huang $H$, Jelicks LA, Chandra M, Loredo ML, Weiss LM, Factor SM, Shtutin V, Mukherjee S, Kitsis RN, Christ GJ, Wittner M, Shirani J, Kisanuki YY, Yanagisawa M: Role of endothelin 1 in the pathogenesis of chronic chagasic heart disease. Infect Immun 2005 , 73:2496-2503

60. Basombrío MA, Nasser JR, Segura MA, Gomez LE: Trypanosoma cruzi: effect of immunization on the risk of vector-delivered infection in guinea pigs. J Parasitol 1997, 83:1059-1062

61. Bernstein DI, Earwood JD, Bravo FJ, Cohen GH, Eisenberg RJ, Clark JR, Fairman J, Cardin RD: Effects of herpes simplex virus type 2 glycoprotein vaccines and CLDC adjuvant on genital herpes infection in the guinea pig. Vaccine 201129:2071-2078

62. Ottenhoff TH, Doherty TM, Dissel JT, Bang P, Lingnau K, Kromann I, Andersen: First in humans: a new molecularly defined vaccine shows excellent safety and strong induction of long-lived Mycobacterium tuberculosis-specific Th1-cell like responses. Hum Vaccin 2010, 6:1007-1015

63. Marin-Neto JA, Rassi A Jr, Avezum A Jr, Mattos AC, Rassi A, Morillo CA, Sosa-Estani S, Yusuf S; BENEFIT Investigators: The BENEFIT trial: testing the hypothesis that trypanocidal therapy is beneficial for patients with chronic Chagas heart disease. Mem Inst Oswaldo Cruz 2009, 104(Suppl 1):319-324

64. Matsuda NM, Miller SM, Evora PR: The chronic gastrointestinal manifestations of Chagas disease. Clinics (Sao Paulo) 2009, 64:1219-1224

65. Padilla-Carlin DJ, McMurray DN, Hickey AJ: The guinea pig as a model of infectious diseases. Comp Med 2008, 58:324-340 